\title{
Separation of some O-Phosphorylated Amino Acids and Peptides on Anion Exchange Resin
}

\author{
L A R S S T R I D \\ Department of Medical Biochemistry, University of Göteborg, Göteborg, Sweden
}

\begin{abstract}
A chromatographic procedure for the separation of O-phosphorylated amino acids and peptides on the anion exchange resin Dowex 1-X2, is described. The following synthetic compounds have been separated: SerP *, ThrP, Gly-SerP-Gly, Gly-SerP, SerP-Gly, LeuSerP, SerP-Leu, SerP-Asp, SerP-Glu and SerP-SerP.
\end{abstract}

$\mathbf{I}^{\mathrm{n}}$ nvestigations of phosphoproteins in this laboratory ${ }^{1-4}$ involve degradation of such proteins by enzymes and by acid, whereby a mixture of phosphorylated amino acids and phosphopeptides are obtained. In the synthesis of phosphopeptides ${ }^{5-7}$, using diphenylphosphoryl chloride as the phosphorylating reagent, a mixture of phosphopeptide and by-products are obtained. Consequently, it was found necessary to work out a simple preparative separation method.

Ion exchange chromatography of phosphopeptides from partial acid hydrolysed phosphoproteins has earlier been used by several researchers. Most of them have used cation exchange resin ${ }^{8,9}$ and in some cases rechromatography on anion exchange resin ${ }^{10-13}$.

Using a cation exchange resin Österberg ${ }^{3}$ obtained a pure phosphopeptide, containing three phosphate groups, from an enzymic digest of casein.

With anion exchange resin Kennedy and Smith ${ }^{\mathbf{1 4}}$ reported complete separation of the phosphates of the following amino acids: hydroxyproline, threonine, serine and tyrosine.

\section{EXPERIMENTAL}

\section{Materials}

All reagents used were of analytical grade.

$2 M$ sodium formate was prepared by mixing equal volumes of $4 \mathrm{M}$ sodium hydroxide and $4 \mathrm{M}$ formic acid. The $\mathrm{pH}$ was adjusted to 5.5 with $4 \mathrm{M}$ formic acid.

* The following abbreviations are used in this paper: SerP is O-phosphorylserine and ThrP is O-phosphorylthreonin. Peptides are abbreviated as commonly done in literature; thus GlySerP-Gly equals glycyl-(O-phosphoryl)-serylglycine (cf. also Table 1).

Acta Chem. Scand. 13 (1959) No. 9 
$0.1 M$ formic acid.

$2 M$ pyridine formate. $511 \mathrm{~g} 90 \%$ formic acid and $790 \mathrm{~g}$ pyridine were mixed and diluted with water to $5 \mathrm{l}$. Resulting $\mathrm{pH}$ was 4.5. From this stock solution, $0.25,0.50$, and $1.00 \mathrm{M}$ solutions were obtained by dilution with water.

Model compounds used in the chromatography are listed in Table 1.

Dowex 1-X2 $\left(\mathrm{Cl}^{-}\right) 200-400$ mesh. $500 \mathrm{ml}$ resin was washed on a Büchner funnel with 2 litres of $2 \mathrm{~N} \mathrm{HCl}$, followed by 2 litres of water. The resin was suspended in water and after the resin had settled for $10 \mathrm{~min}$, the supernatant was decanted to remove the finest particles. Coarse particles were removed by wet screening through a 50 DIN sieve. The resin was then poured into a column and converted to the formate form by allowing $2 \mathrm{M}$ sodium formate $\mathrm{pH} \mathbf{5 . 5}$ to flow slowly through the column, until the effluent gave a negativ test for chloride. It was then washed with distilled water on a Büchner funnel and stored in moist form.

\section{Method}

Column. About $150 \mathrm{ml}$ of the resin was washed with $700 \mathrm{ml} 0.1 \mathrm{M}$ formic acid and then suspended in $200 \mathrm{ml}$ of the same acid and freed from air by evacuation. The suspended resin was poured into a column $1.6 \times 50 \mathrm{~cm}$ to a height of $43 \mathrm{~cm}$ at a pressure of $15 \mathrm{~cm} \mathrm{Hg}$. The top of the column was connected to a mixing chamber of $550 \mathrm{ml}$, furnished with a magnetic stirrer. The mixing chamber was connected to a separatory funnel. The top of the column, mixing chamber and separatory funnel were all filled with $0.1 \mathrm{M}$ formic acid, and after $100 \mathrm{ml}$ acid had prssed, the column was ready for use.

Chromatography. $0.5-2 \mathrm{mg}$ of each component (Table I) in $0.1-0.2 \mathrm{ml} \mathrm{H}_{2} \mathrm{O}$ or $0.1 \mathrm{M}$ formic acid was applied to the column and washed into it by washing twice with $0.2 \mathrm{ml}$ of $0.1 \mathrm{M}$ formic acid. The gradient system was connected, and elution started. The following elution schedule was used with the gradient given as limit concentration:

I $0.1 \mathrm{M}$ formic acid $(165 \mathrm{ml}$ )

II Gradient to $0.25 \mathrm{M}$ pyridine formate, $\mathrm{pH} 4.5(725 \mathrm{ml})$

III Gradient to $0.50 \mathrm{M}$ pyridine formate, $\mathrm{pH} 4.5(310 \mathrm{ml})$

IV Gradient to $1.00 \mathrm{M}$ pyridine formate, $\mathrm{pH} 4.5(320 \mathrm{ml})$

Fractions of $3.5 \mathrm{ml}$ were collected. For the sake of convenience the flow rate in the experiment described here was $20 \mathrm{ml} / \mathrm{h}$ but can be increased considerably. The chromatographic run was performed at room temperature.

Analysis and identification of the eluate. $1 \mathrm{ml}$ of each fraction was mixed with $1 \mathrm{ml}$ of $0.2 \mathrm{M}$ citrate buffer $\mathrm{pH} 5.0$. $1 \mathrm{ml}$ of ninhydrin solution was added ${ }^{16}$ and the sample heated for $15 \mathrm{~min}$ in boiling water. After dilution with $10 \mathrm{ml}$ of ethanol:water (1:1), the optical density was read at $570 \mathrm{~m} \mu$.

Table 1. Model compounds.

\begin{tabular}{ll}
\hline \multicolumn{1}{c}{ Compound * } & Abbreviation \\
\hline O-Phosphorylserine & SerP \\
Glycyl-(O-phosphoryl)-serine & Gly-SerP \\
O-Phosphorylserylglycine & SerP-Gly \\
Glycyl-(O-phosphoryl)-serylglycine & Gly-SerP-Gly \\
Leucyl-(O-phosphoryl)-serine & Leu-SerP \\
O-Phosphorylseryl-leucine & SerP-Leu \\
O-Phosphorylserylglutamic acid & SerP-Glu \\
O-Phosphorylserylaspartic acid & SerP-Asp \\
O-Phosphorylseryl-(O-phosphoryl)-serine & SerP-SerP \\
O-Phosphorylthreonine & ThrP \\
Aspartic acid & Asp \\
Serine & Ser \\
\hline
\end{tabular}

* The three last mentioned compounds were obtained from Mann Research Lab., N.Y. All other compounds were synthesized in this laboratory $5,6,15$. 


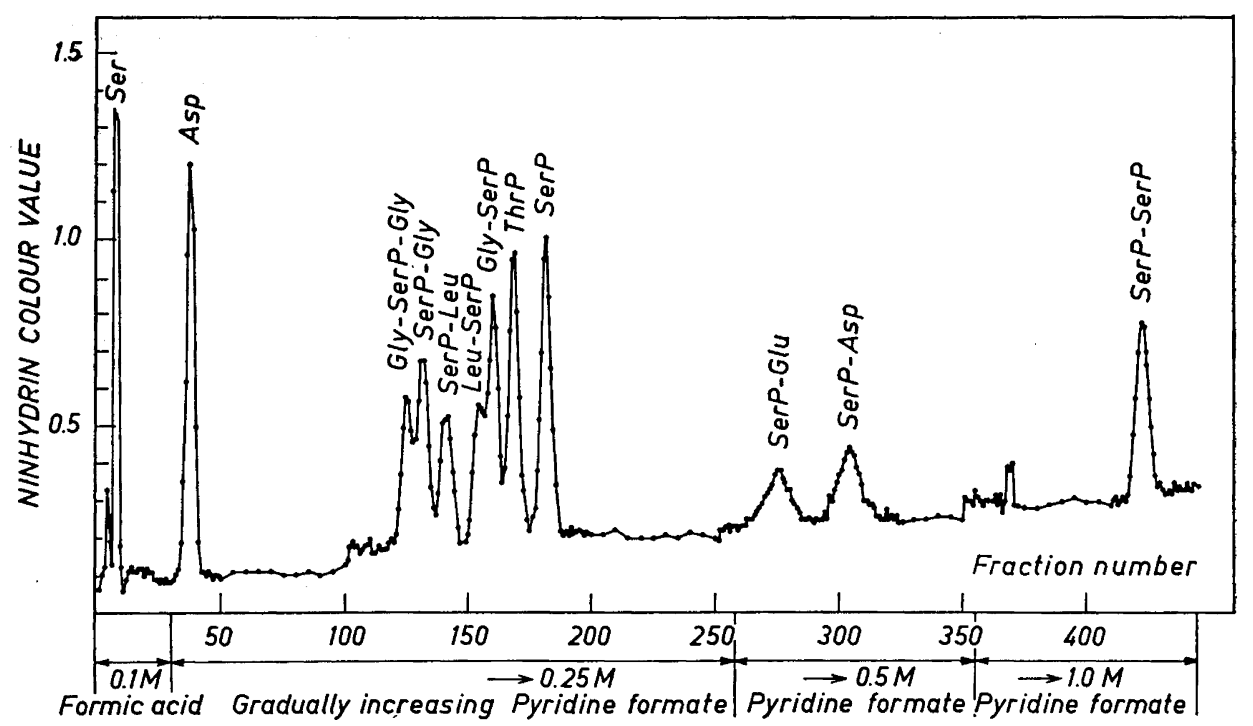

Fig. 1. Chromatogram obtained by separation of a synthetic mixture of phosphorylated amino acids and peptides. Dimensions of the column $1.6 \times 43 \mathrm{~cm}$. Volume of each fraction $3.5 \mathrm{ml}$. $1 \mathrm{ml}$ of each fraction was used for the colour reaction.

The fractions from each peak were combined. Wherever overlapping occurred the intermediate fractions were discarded. The solutions were evaporated to dryness at $40^{\circ}$ in vacuo. A small amount of water was added and the evaporation repeated until no smell of pyridine could be detected. As it was sometimes difficult to free the product from pyridine ${ }^{\circ}$, particularly the slower fractions in the chromatography, it was found convenient to remove the pyridine on a small Dowex $50\left(\mathrm{H}^{+}\right)$column and to elute the peptide with water or weak acid.

Identification of the peaks was made from runnings where certain compounds were omitted, and by comparison between the applied and recovered ninhydrin colour.

The peaks were also identified by paper chromatography with the solvent system ButOH:HAc: $\mathrm{H}_{2} \mathrm{O}(4: 1: 5)$. Each fraction gave only one spot. $R_{F}$-values and colours were compared with references (Table 1).

\section{RESULTS AND DISCUSSION}

It is evident that chromatography on anion exchange resin is useful for the separation of acidic substances such as phosphorylated peptides. These compounds are often so acidic that they are difficult to adsorb on cation exchange resins. On strong anion exchange resins on the other hand they are strongly retained. The resin Dowex 1-X2, being a strong anion exchanger, was used in this investigation. The low cross-linking was chosen to allow separation also of larger peptides.

Concerning elution medium the requirements were firstly that it should be easy to evaporate at temperatures where phosphopeptides are stable, and secondly that it should not produce colour reaction with ninhydrin. Pyridine formate meets these requirements and was therefore selected.

Acta Chem. Scand. 13 (1959) No. 9 
Synthetic phosphorylated amino acids and peptides 5,6,15 were used for working out the method. Serine and aspartic acid have been included to show where a neutral and acidic amino acid is eluted.

Fig. 1 shows a typical chromatogram. It can be seen that the more acidic the compounds, the more difficult they are to elute from the column. SerPSerP, containing two phosphate groups per two amino acid residues, is the most acidic of the applied compounds, and is not eluted until the concentration of pyridine formate in the solvent is about $0.8 \mathrm{M}$. The phosphopeptides containing acidic amino acids are somewhat less acidic. They also show a strong binding to the column and are eluted in the order expected.

Phosphorylated amino acids and phosphopeptides containing neutral amino acids are eluted within a rather narrow region. Gly-SerP-Gly contains one phosphate group per three amino acid residues and is, as expected, eluted first. The phosphorylated derivatives of threonine and serine, having one phosphate group per amino acid residue, are eluted after the phosphopeptides containing neutral amino acids. The order of elution between the compounds agrees fairly well with the order of the $\mathrm{p} K$ values for their carboxyl groups, reported ${ }^{17}$ by Fölsch and Österberg as being: Gly-SerP-Gly 3.29, SerP-Gly 3.13, SerP-Leu 3.11, Gly-SerP 2.90 and SerP 2.07.

As the method has been worked out for preparative use, no exact determinations of the recovery have been performed. The ninhydrin colour of each compound indicates a yield of between $85-107 \%$.

With slight modifications the present method has been used for isolation of phosphorylated peptides from products obtained by hydrogenation of $\mathrm{O}$-diphenylphosphorylated peptide derivatives ${ }^{6,7}$.

Acknowledgement. The author wishes to express sincere thanks to Professor Olof Mellander for his support in this work.

The work was supported by grants from the Swedish Medical Research Council to Professor Olof Mellander.

\section{REFERENCES}

1. Mellander, O. Upsala Läkarfören. Förh. 52 (1947) 107.

2. Mellander, O. and de Verdier, C.-H. Acta Soc. Med. Upsaliensis 57 (1952) 218.

3. Österberg, R. Arkiv Kemi 13 (1959) 409.

4. Bennich, H., Johansson, B. and Österberg, R. Acta Chem. Scand. 13 (1959) 1171.

5. Fölsch, G. Acta Chem. Scand. 12 (1958) 561.

6. Fölsch, G. Acta Chem. Scand. 13 (1959) 1407.

7. Theodoropoulos, D., Bennich, H., Fölsch, G. and Mellander, O. Nature. 184 (1959) 187.

8. Schaffer, N. K., May, S. C., Jr. and Summerson, W. H. J. Biol. Chem. 202 (1953) 67.

9. Schaffer, N. K., Simet, L., Harshman, S., Engle, R. R. and Drisko, R. W. J .Biol. Chem. 225 (1957) 197.

10. Flavin, M. J. Biol. Chem. 210 (1954) 771.

11. Hipp, N. J., Groves, M. L. and McMeekin, T. L. J. Am. Chem. Soc. 79 (1957) 2559.

12. de Verdier, C.-H. Acta Chem. Scand. 7 (1953) 196.

13. de Verdier, C.-H. Acta Chem. Scand. 8 (1954) 1302.

14. Kennedy, E. P. and Smith, S. W. J. Biol. Chem. 207 (1954) 153.

15. Fölsch, G. and Mellander, O. Acta Chem. Scand. 11 (1957) 1232.

16. Moore, S. and Stein, W. H. J. Biol. Chem. 211 (1954) 907.

17. Fölsch, G. and Österberg, R. J. Biol. Chem. 234 (1959) 2298.

Received July 27, 1959. 